\title{
A systematic review of barriers and motivators to physical activity in elderly adults in Iran and worldwide
}

\author{
SoudabehYarmohammadi ${ }^{1}$,Hossein MozafarSaadati ${ }^{2}$, Mohtasham Ghaffari ${ }^{3}$,Ali Ramezankhani ${ }^{4}$ \\ 'Student Research Committee, Department and Faculty of Health Education and Health Promotion, Shahid Beheshti University of Medical \\ Sciences, Tehran, Iran; '2Department of Epidemiology, School of Public Health and Safety, Shahid Beheshti University of Medical Sciences, \\ Tehran, Iran; ${ }^{3}$ Environmental and Occupational Hazards Control Research Center, School of Public Health and Safety, Shahid Beheshti \\ University of Medical Sciences, Tehran, Iran; ${ }^{4}$ Department of Public Health, School of Public Health and Safety, Shahid Beheshti University of \\ Medical Sciences, Tehran, Iran
}

OBJECTIVES: This study was conducted to identify and characterize the barriers and motivations to physical activity (PA) for elderly adults in Iran and other countries.

METHODS: We searched 6 databases (PubMed, Embase, Scopus, Web of Science, Magiran, and the Scientific Information Database) from 2000 to the November 2017, using "aged 60 and over," "physical activity" or "exercise," and "motivator" and "barrier" as keywords. Two reviewers independently performed the search, screening, and quality assessment of the studies.

RESULTS: In total, 34 papers were finally included in the study. The most important barriers, based on the frequency of factors, included physical problems, having no companions, and physical barriers to walking. The motivators included improving one's physical condition, being social, and suitability of the physical environment.

CONCLUSIONS: Important motivators and barriers to PA were more closely related to intrapersonal factors than to the interpersonal and environmental domains. The barriers and motivators to PA in the elderly were not markedly different between Iran and other countries. Therefore, a general strategy could be designed to improve PA in the elderly.

KEY WORDS: Motivation, Sedentary behavior, Exercise, Motor activity, Aging

\section{INTRODUCTION}

On one hand, physical activity (PA) helps elderly people to improve their strength and flexibility, although the most effective type of activity is still unclear [1]. On the other hand, the elderlydue to health problems and insufficient facilities-are more likely to face barriers to access than others [2].

For adults aged 60 and over, important motivations for PA have

\section{Correspondence: Ali Ramezankhani}

Department of Public Health, School of Public Health and Safety, Shahid Beheshti University of Medical Sciences, Shahid Chamran Highway, Tehran 198353-5511, Iran

E-mail: aramezankhani2018@gmail.com

Received: Jun 16, 2019 / Accepted: Nov 29, 2019/ Published: Nov 29, 2019

This article is available from: http://e-epih.org/

(c) This is an open-access article distributed under the terms of the Creative Commons Attribution License (http://creativecommons.org/licenses/by/4.0/), which permits unrestricted use, distribution, and reproduction in any medium, provided the original work is properly cited.

(C) 2019 , Korean Society of Epidemiology been reported to include social support, health benefits, and enjoyment, while the main barriers have been found to be insufficient guidance and a lack of role models [3]. For people aged over 80 years, the most important motivators and barriers have been reported to be the health benefits of PA, various types of fears, individual preferences, and social support [4]. In general, due to the increasing percentage of the older population in developing (lowand middle-income) countries and the burden of health care and treatment costs, reducing the prevalence of physical inactivity has received attention as an important goal [5]. In addition, PA develops as a behavior through complex and dynamic interrelations among individual, social, and environmental factors, underscoring the usefulness of using multidimensional models to study PA $[6,7]$. As an example of this approach, the socio-ecological model of McLeroy et al. [8] was used to study the barriers and motivations to PA in the elderly. The aim of this study was to systematically review the motivators and barriers to PA in people aged 60 years and older in Iran and other countries. 


\section{MATERIALS AND METHODS}

\section{Search strategy}

To collect the data, a comprehensive search was performed of several electronic databases (PubMed [MeSH terms], Web of Science, Scopus, Embase, Scientific Information Database, Magiran) to identify all potentially relevant publications in the Persian and English languages from 2000 to November 2017. The following keywords were used: "aged (or age 60 and over)," "physical activity (or exercise)," and "motivator and barrier" (Supplementary Material 1). The detailed search strategy implementation in PubMed was as follows: ([elderly OR Aged OR "60 over aged”] AND ["Physical activity" OR "Exercise" OR "Physical exercise" OR "Motor activity"] AND [Motivation OR Motivat* OR Barrier*]). The inclusion criteria were (1) articles published in the Persian and English languages; (2) original research examining the barriers and motivators to PA in the elderly; (3) studies that examined outcomes in terms of physical and mental illness among the elderly (aged 60 and over); and (4) studies conducted from from 2000 to
November 2017. The exclusion criteria were non-original articles (i.e., letters to the editor, case reports, interventional studies, reviews, meta-analyses, and articles presented at seminars and conferences were excluded), articles with no specific definition of age, those that were conducted before 2000 but were accepted in 2000 or later, articles analyzing elderly individuals living in nursing homes, and articles with a very low quality score. In addition, a backward search (checking bibliographic mining of identified papers for any additional studies) was conducted to identify any studies that were not retrieved using the main search strategy. All quantitative and qualitative designs were included. In total, 1,981 articles were retrieved, of which a total of 34 articles remained after the review process shown in Figure 1. Finally, 2 authors carefully examined 34 full-text articles.

In this study, 2 types of studies were investigated: (1) quantitative studies (5 from Iran and 15 from other countries); (2) qualitative studies ( 1 from Iran and 13 from other countries).

There were 6 studies in Persian and 28 studies in English.

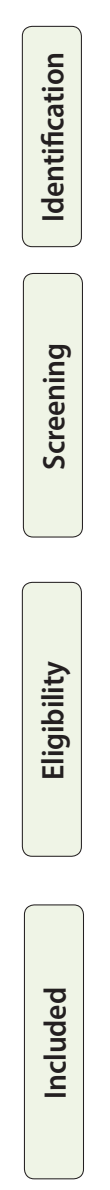

Additional records identified

through other sources $(n=0)$
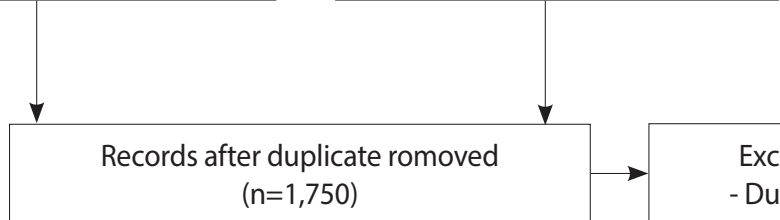
$(n=1,750)$ - Duplicate articles

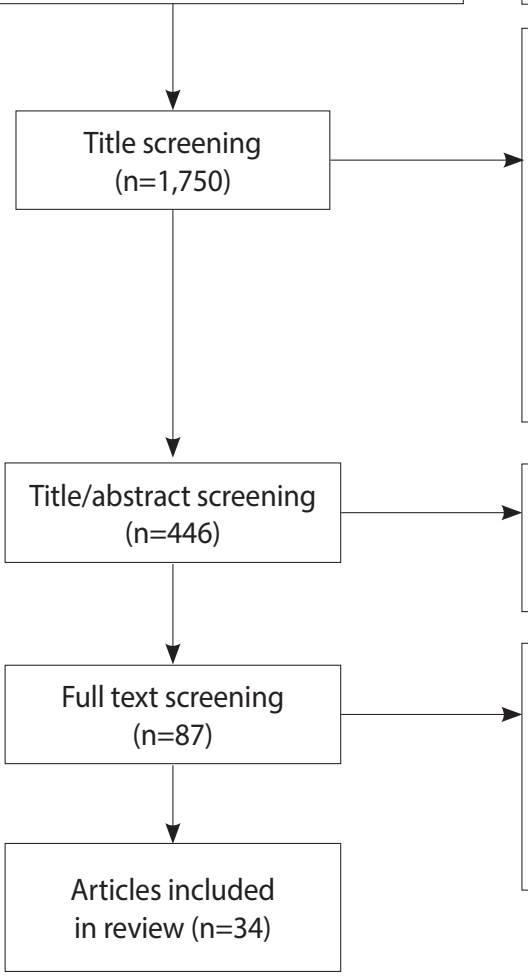

Excluded $(n=1,304)$

- No abstract

- Letter to editor

- Case report

- Intervention studies

- Systematic review

- Seminars and conferences

- Books

- Irrelevant

Excluded $(n=359)$

- Non-adult studies

- Comments, editorial

Excluded $(n=53)$

- Full text not available

- Definition of outcome

- Data not in usable format

- Irrelevant

Figure 1. The literature review and retrieval process. 


\section{Evaluating the quality of articles}

The quality of qualitative studies was assessed using the qualitative methodological checklist of the National Institute of Clinical Nursing (NICE) [9]. In general, according to the NICE checklist, ++ means that all or most of the checklist criteria have been fulfilled, + means that some of the checklist criteria have been fulfilled, and - means that few or no checklist criteria have been fulfilled. Quantitative studies were assessed using the Newcastle-Ottawa Quality Assessment Scale (NOS) adapted for cross-sectional studies [10]. The NOS is based on 3 domains, including the selection of study groups, the comparability of groups, and the description of exposures and outcomes. This scale, which includes 8 items is scored in terms of stars, assesses the quality of each study in each domain. All items except the comparability domain have 1 star, while the maximum score for the comparability domain is 2 stars. The total number of earned stars is calculated as the total quality score for each study, which ranges from 1 star (very poor) to 10 stars (high quality). Studies were classified as high-quality (8-10), medium-quality (6-7), or low-quality $(<6)$. Two review authors (SY and HMS) completed the quality assessment independently. In cases of disagreement or items that remained unclear, a third review author (AR or MG) was consulted.

\section{Data extraction}

We used a structured form to extract the data. The extracted data included study and participant characteristics (e.g., gender, location, country, population, age, type of instrument, type of study, year of study), as well as motivators and barriers to PA. Two authors (SY and HMS), who conducted the study selection independently, performed the data extraction. Any disagreements were discussed with a third review author (AR or MG) if necessary. The data were classified using the socio-ecological model that McLeroy et al. [8] developed in 1988 as a theoretical framework involving interpersonal and intrapersonal factors, organizational and social factors, and environmental factors (Figure 2). The identified factors were prioritized based on the frequency of participants' responses.

\section{Ethics statement}

This study is a systematic review and does not deal with human participants.

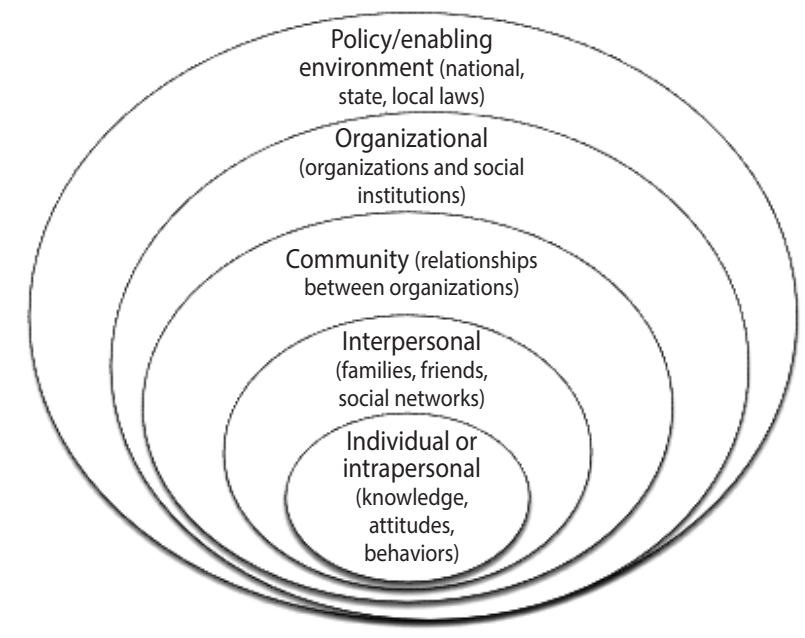

Figure 2. Levels of impact in the socio-ecological model. Adapted from McLeroy et al. Health Educ Q 1988;15:351-377 [8].

Table 1. Quality assessment of qualitative articles

\begin{tabular}{|c|c|c|c|c|c|c|c|c|c|c|c|c|}
\hline Study & 1.1 & 1.2 & 2.1 & 3.1 & 4.1 & 4.2 & 5.1 & 5.2 & 5.3 & 5.4 & 6.1 & 6.2 \\
\hline Yoo et al. 2017 [11] & + & + & + & + & + & + & + & + & + & + & $?$ & $?$ \\
\hline Horne et al. 2012 [12] & + & + & + & + & + & + & + & + & + & + & + & $?$ \\
\hline Welmer et al. 2012 [13] & + & + & + & + & - & + & + & + & + & + & + & $?$ \\
\hline Simmonds et al. 2016 [14] & + & + & + & + & + & + & + & + & + & + & + & $?$ \\
\hline Bethancourt et al. 2014 [15] & + & + & + & + & + & + & + & + & + & + & + & + \\
\hline Nadri et al. 2016 [16] & + & + & + & + & + & + & + & + & + & + & + & + \\
\hline Costello et al. 2011 [17] & + & + & + & + & + & + & $?$ & + & + & + & $?$ & $?$ \\
\hline De Groot et al. 2011 [18] & + & + & + & + & + & + & $?$ & + & + & + & + & + \\
\hline Lees et al. 2005 [19] & + & $?$ & + & + & + & + & $?$ & + & + & + & $?$ & $?$ \\
\hline Grossman et al. 2003 [20] & + & + & $?$ & + & $?$ & + & + & $?$ & + & + & $?$ & - \\
\hline Chastin et al. 2014 [21] & + & + & $?$ & + & + & + & + & + & + & + & + & $?$ \\
\hline Chen et al. 2015 [22] & + & + & + & + & + & + & + & $?$ & + & + & $?$ & $?$ \\
\hline Chippendale et al. 2015 [23] & + & + & $?$ & + & $?$ & + & + & + & + & $?$ & + & + \\
\hline Miller et al. 2017 [24] & + & + & + & + & + & + & + & + & + & + & $?$ & $?$ \\
\hline
\end{tabular}

1.1 , whether the qualitative approach is appropriate; 1.2 , whether it is clear what the study is doing; 2.1 , how defendable is the research design/ research methodology?; 3.1, how were the data collected?; 4.1 , whether the text was clearly explained; 4.2, whether the methods were reliable; 5.1, whether the data were rich; 5.2, whether the analysis was reliable; 5.3 , whether the findings are persuasive; 5.4, whether the conclusion is sufficient; 6.1 , whether the study was approved by an ethics committee; 6.2 , whether the role of the researcher was clearly explained; + , appropriate/clear/ defendable/persuasive/rich/yes; -, inappropriate/not defendable/not clear/not persuasive/not/poor; ?, I'm not sure/combined/reported. 


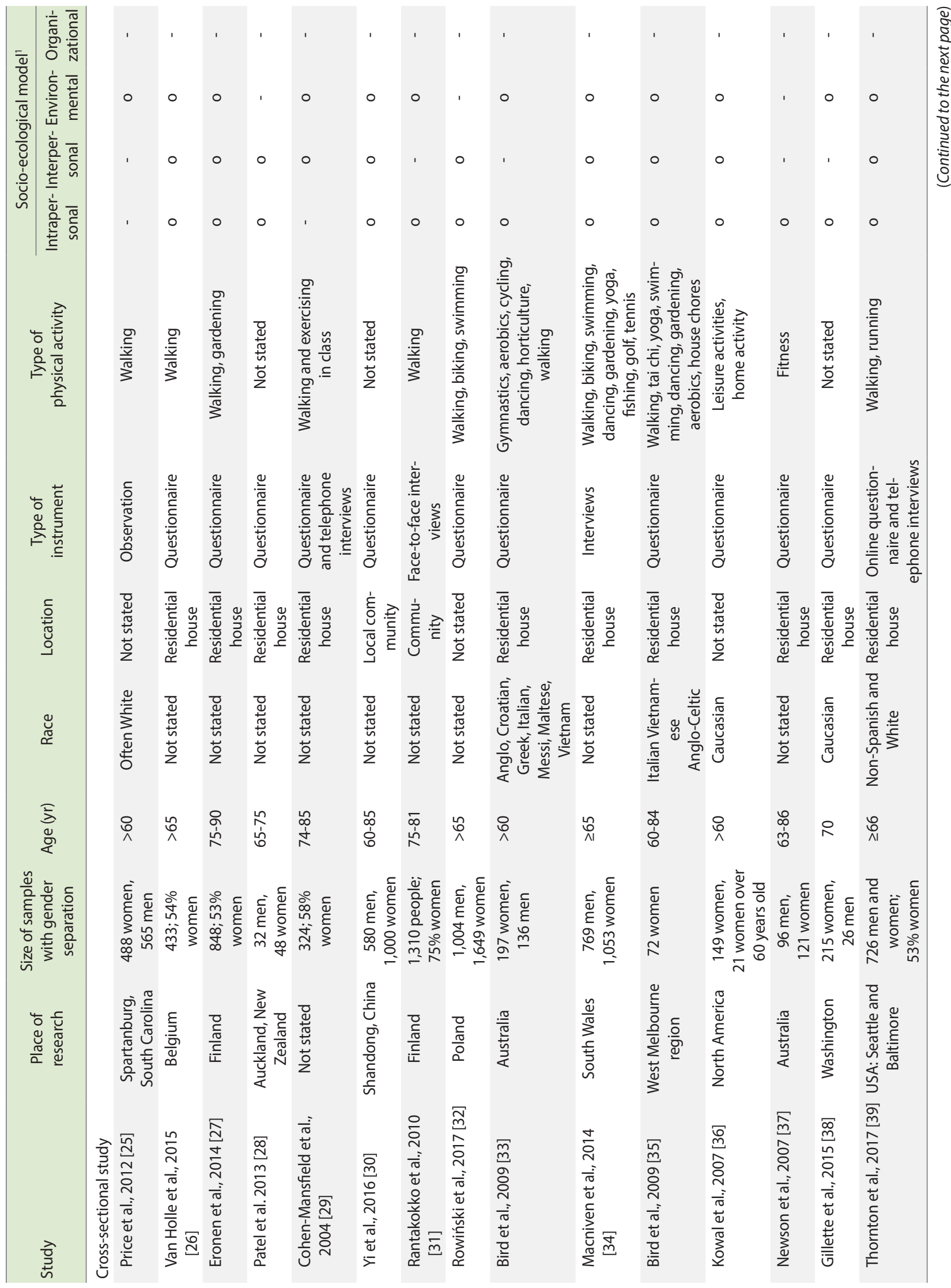




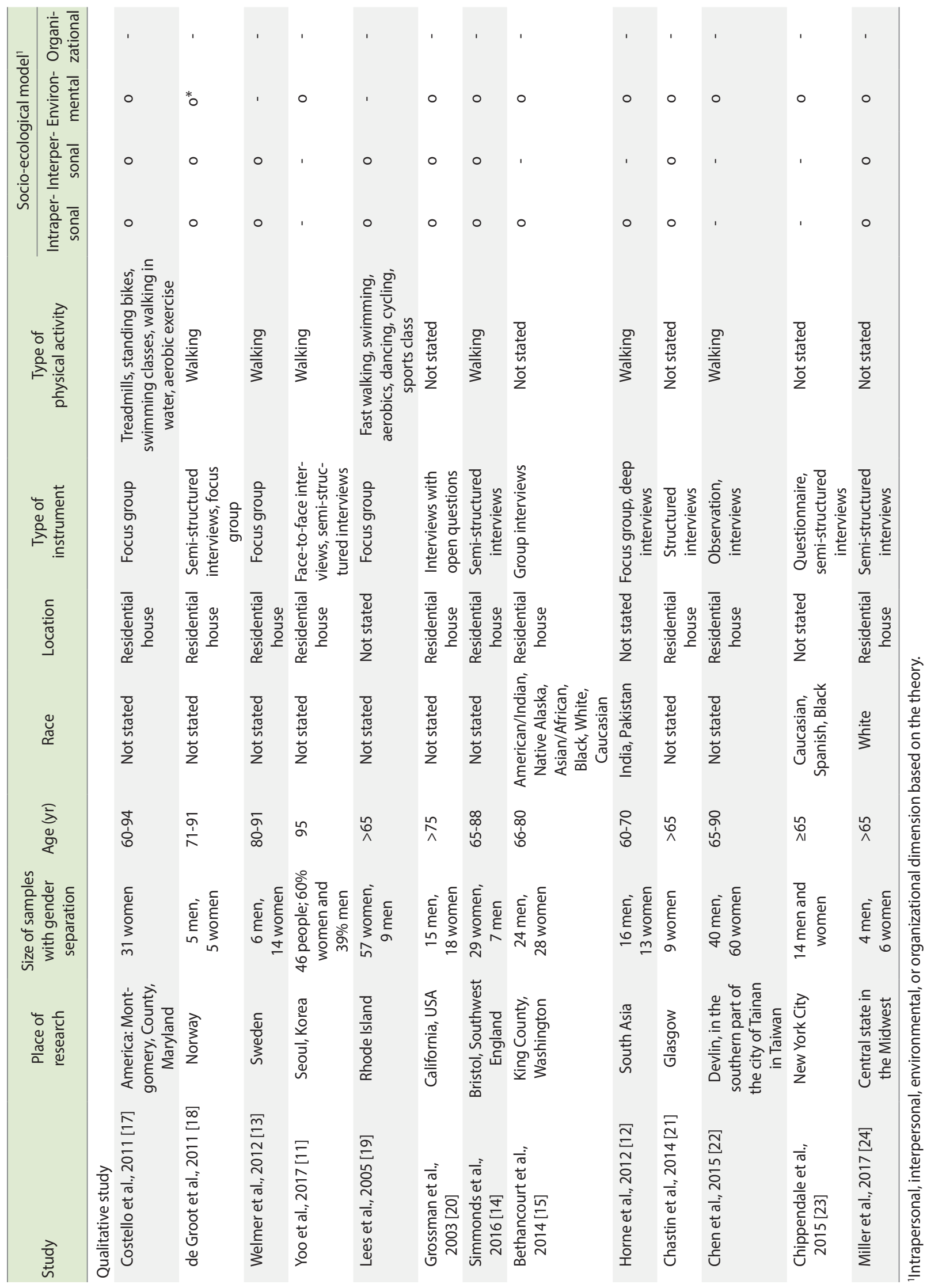




\section{RESULTS}

\section{Quality of qualitative and quantitative studies}

Fortunately, almost all the qualitative studies followed the items in the NICE checklist for qualitative studies. Two of the 14 qualitative articles were high-quality, 12 were good-quality, and 5 were poor-quality, as indicated in Table 1 . The quantitative studies were evaluated using the NOS scale, and 18 articles were found to be moderate- to high-quality, while 2 were moderate-quality.

\section{Description of reviewed studies}

The articles were published between 2000 and November 2017, and the sample sizes ranged from 9 (in a qualitative study) to 4,227 participants (in a quantitative study). The samples consisted of both men and women subjects in 30 of the 34 studies, exclusively of women subjects in 4 studies, and exclusively of men subjects in 1 study. The most common type of PA was walking, followed by swimming and fitness, and a description of the type of PA was not available in 17 studies.

In Tables 2 and 3, the characteristics and major findings of the studies are presented.

\section{Motivators and barriers to the physical activity among the elderly}

In the framework of the McLeroy model, we examined the motivators and barriers to PA among the elderly in the intrapersonal, interpersonal, and environmental domains as follows (Tables 2 and 3). According to the study population-people aged 60 years and older-the items from the organizational domain of the McLeroy model were excluded. For quantitative studies, only significant variables were evaluated. Due to the heterogeneity across studies and input variables, it was not possible to conduct a metaanalysis of the results. Below, the most important factors for all dimensions of the model, based on the frequency of participants' responses, are presented.

\section{Intrapersonal factors}

Through the literature review, 23 barriers and 16 motivators were identified as intrapersonal factors. In several articles, physical problems - such as difficulty in walking, physical health problems, physical weakness, respiratory problems, and lack of energy-were mentioned as key barriers [ [13,14,16,19,27,31-34,36, 38-41,43-45]. Time limits were the second most important barrier related to intrapersonal factors $[16,17,19,27,28,35,36,39,42-44]$. The third most important intrapersonal barrier was fear of falling $[14,17,19,23,27,31,35,40,43,45]$.

The most important intrapersonal set of motivators that resulted in PA was improving one's physical condition, which included improving one's balance and walking ability, reducing muscle pain, improving sleep, and strengthening one's muscles $[18,24,34,41,44]$. Enjoyment [12,24,40,44], addressing psychological issues (which involved relief from stress, feeling more efficient, having positive perceptions of PA, having a positive self-image, being less depressed,

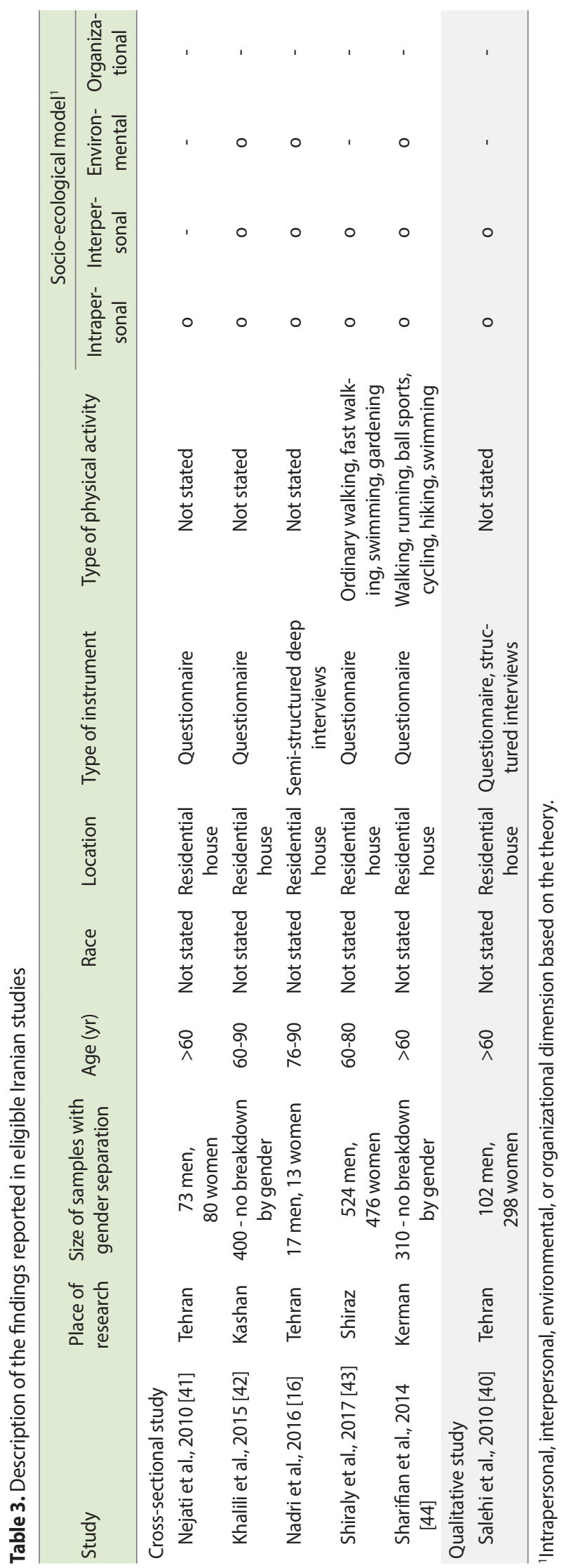


Table 4. Motivations and barriers to physical activity for the elderly

\begin{tabular}{|c|c|c|}
\hline \multirow{2}{*}{ Dimensions } & \multicolumn{2}{|c|}{ Physical activity } \\
\hline & Barriers & Motivators \\
\hline \multirow[t]{26}{*}{ Intrapersonal } & Physical problems $[13,14,16,19,27,31-34,36,38-41,43-45]$ & Improving one's physical condition $[18,24,28,34,41,44,45]$ \\
\hline & Time limits $[16,17,19,27,28,35,36,39,42-44]$ & Enjoyment $[12,24,28,40,44,45]$ \\
\hline & Fear of falling $[14,17,19,23,27,31,35,40,43,45]$ & Understanding psychological issues $[14,16,33,41]$ \\
\hline & Fatigue $[17,19,21,33,35,42]$ & Having motivation and access to physical activity resources \\
\hline & Lack of interest $[14,16,32,34,36,44]$ & {$[15,30,34,38]$} \\
\hline & & Lack of knowledge $[17,30]$ \\
\hline & Lack of motivation $[16,28,32,33,35,43]$ & Health concerns $[17,37]$ \\
\hline & Pain $[21,24,38,41,43]$ & Being economical $[24,34]$ \\
\hline & Laziness $[19,36,40,44]$ & Feeling security [33] \\
\hline & Financial cost $[13,24,32,34]$ & Having a long life [40] \\
\hline & & Fear of falling and illness [13] \\
\hline & Age $[42-44]$ & Pain [21] \\
\hline & Issues related to individual beliefs $[13,17]$ & Loneliness [35] \\
\hline & Household chores $[34,36]$ & Socioeconomic status, having sports skills, training [30] \\
\hline & Security concerns $[14,23]$ & Having enough time [12] \\
\hline & Single and widower status $[24,43]$ & Joining physical activity to daily life [14] \\
\hline & & Spending free time [44] \\
\hline & Being active enough [28] & \\
\hline & Sex $[43]$ & \\
\hline & Lack of energy [21] & \\
\hline & Insufficient understanding of physical activity [42] & \\
\hline & An unpleasant experience [18] & \\
\hline & Lack of self-discipline [17] & \\
\hline & Low level of education, retirement, life problems [43] & \\
\hline & Heavy weight [42] & \\
\hline & Feeling self-awareness [39] & \\
\hline \multirow[t]{6}{*}{ Interpersonal } & Having no companion $[36,42]$ & Being social $[11,16,18,23,24,26,28,30,36,40]$ \\
\hline & Family responsibilities [34] & Specialist health care $[18,28,29]$ \\
\hline & $\begin{array}{l}\text { Having no professional guidance, inadequate information } \\
\text { [15] }\end{array}$ & Availability of facilities $[15,24]$ \\
\hline & $\begin{array}{l}\text { Social pressure, having less time to spend with friends and } \\
\text { family [21] }\end{array}$ & Having a companion for exercise, fear of dependency [13] \\
\hline & $\begin{array}{l}\text { Exercise clubs devoted to young adults and the lack of } \\
\text { planning in the at clubs [23] }\end{array}$ & Assessment of exercise program by a professional instructor [29] \\
\hline & Working with others, different views of others [16] & Social pressure [21] \\
\hline \multirow{9}{*}{$\begin{array}{l}\text { Environmen- } \\
\text { tal }\end{array}$} & Physical barriers to walking $[22,23,26,27,31,43,44]$ & Suitability of the physical environment $[11,23,26,34,36]$ \\
\hline & Temperature, season, and weather $[16,25,27,34,35]$ & Environmental security $[26,30]$ \\
\hline & Lack of facilities for exercise $[16,21,34,36]$ & \\
\hline & & Access to public transportation [11] \\
\hline & & Access to sports facilities [30] \\
\hline & Traffic $[16,36]$ & $\begin{array}{l}\text { Social network of neighbors, air quality, living in an apartment, } \\
\text { proximity to sports facilities [23] }\end{array}$ \\
\hline & Inappropriateness of the timing of sports classes $[16,23]$ & Economic and financial agents, holding walking meetings [16] \\
\hline & Lack of personal safety [16] & \\
\hline & Commuting and distance from home to sports facilities [23] & \\
\hline
\end{tabular}

and enhancing sleep $[14,16,33,41])$, and increasing motivation and access to PA resources $[15,30,34,38]$ comprised the second most important set of intrapersonal motivators [12,24,28,40,44,45].
The third most important set of intrapersonal motivators included a lack of knowledge [17,30], health concerns [17,37], and being economical [24,34]. 


\section{Interpersonal factors}

In the interpersonal domain, 6 barriers and 7 motivations were identified (Table 4). The most important interpersonal barrier to PA was having no companion [36,42]. Family responsibilities (taking care of grandchildren, children, and sick people at home) were the second most important interpersonal barrier to PA [34].

The most important interpersonal motivator was being social, which included communication with friends, peer support, communication with others, exercise with friends, social coherence, moderate and high local dependency, an abundance of companions for walking, and support from others $[11,16,18,23,24,26,28$, $30,36,40]$. Supervision of health professionals was the second interpersonal motivator $[18,28,29]$. In addition, 3 articles identified specialist health care $[18,28,29]$ as a motivator for PA. Another important interpersonal motivator for PA was the availability of sports facilities $[15,24]$.

\section{Environmental factors}

Overall, 7 barriers and 6 motivators were identified at the community level. The most important barrier was physical barriers to walking, which included problems related to safety, parked motorcycles next to the street, potted plants, rubber tiles in playgrounds, food retailers, paved streets, broken sidewalks, scaffolds, snow accumulation along the street in winter, devoted seats in parks for children, the lack of facilities such as benches for resting, poor locations, unsafe roads, stray dogs, and hills [22,23,26,27,31,43,44]. The second most important set of barriers were related to temperature, season, and weather $[16,25,27,34,35]$. More intense PA among the elderly was observed in the spring $(40.1 \%)$, in sunny weather (76.8\%), and at moderate temperatures (56.2\%) [25]. The third most important barrier was a lack of facilities for exercise $[16,21,34,36]$.

The most important environmental motivator was the suitability of the physical environment. This factor included pleasant landscapes, streetlights, sidewalks, bike riding routes, walking paths, the neighborhood's suitability for walking, interconnections between streets and an attractive environment, an environment free from non-cultural social activities (e.g., smoking, drinking alcohol, gambling), green space, attractive architecture, benches for resting, a place for dog parks, a smooth surface for hiking, and food availability in urban centers [11,23,26,34,36]. Environmental security was the second environmental motivator $[26,30]$.

\section{DISCUSSION}

In the present study, information on PA among the elderly was reviewed from 2000 to November 2017. We aimed to identify the motivators and barriers to PA among individuals aged over 60 in Iran and worldwide; therefore, some studies were excluded because they did not analyze participants under or over 60 years of age as 2 different groups [2,36]. In general, the ecological model is a comprehensive multilevel framework that includes contributors to active behavior at all levels: individual (interpersonal and in- trapersonal), social, environmental, and policy [47].

A systematic review by Baert et al. [4] on adults aged over 79 confirmed that quantitative research has a greater focus on the interpersonal and community levels, while qualitative research tends to focus more on the interpersonal level. We found that more research is needed into barriers and motivators at the organizational level, while Baert et al. [4] showed that community-based barriers and motivators need more research because policy-makers may be able to exert influence on these factors.

\section{Intrapersonal factors}

Health status was highlighted in most articles, either as a barrier (18 times) or as a motivator ( 5 times) for PA. To summarize, in the literature review, 23 articles reported that poor health was a relevant factor for PA among those aged 60 and over. Moreover, the beneficial effects of PA on health status (such as improving balance, improving walking ability, reducing muscle pain, improving sleep, and strengthening) are well established. In addition, Baert et al. [4] reported that health status was both a barrier and motivator. Nonetheless, health improvement has been reported as an important motivator, and research has highlighted that health benefits can be a major factor for promoting PA [17]. In this review, most studies were conducted in Iran and the USA. In these countries, special consideration should be given to the proportion of the young population in light of current barriers. For example, since Iran is a country with a young population, the proportion of the elderly in Iran is expected to peak in the next 50 years, and Iran will face similar challenges to Europe and the USA between 2040 and 2050 [48].

Fear emerged as a special barrier. Fear is a complex phenomenon that can occur in different situations (e.g., fear of walking at night in order to exercise outside the house). It can be related to health status, such as fear of injury or pain, fear of falling, and fear of being dependent on others. Lim \& Taylor [49] reported that fear of falling was associated with inadequate levels of PA. Moreover, fear of falling was identified as a barrier to PA in different races, including African-Americans, Whites, and American Indians. In particular, American Indians were worried about falling when there was nobody to help them [50]. Furthermore, anxiety and fear of injury were mentioned as a barrier [19]. Health care providers should recognize this type of fear, and should consider it as an important barrier to be dealt with appropriately, if necessary.

In our study, time limits or lack of time was identified as a barrier. This barrier has also been described in other studies [4]. In a focus group study, lack of time among people aged over 65 was found to be a barrier to PA [19]. In many countries and cultures, the responsibilities of taking care of children and the home take up many hours in the day, with consequent negative effects on health behavior [51].

Enjoying PA was reported as a motivator, as in other studies. Factors related to enjoyment increase the pleasure experienced during $\mathrm{PA}$, which depends on individual preferences (doing physical exercise in a group or enjoying the landscape). Fortunately, health care 
providers can provide support and guidance in this respect [4].

\section{Interpersonal factors}

As has been found for other age groups, being social was identified as a motivator. In general, social support was also reported as a motivational factor. However, elderly individuals need more social support than younger adults [4]. Unfortunately, elderly people are often single, causing them to be socially isolated [24]. Supervision by health professionals has an important impact on PA in the elderly; in particular, health care providers can encourage elderly people to participate in group exercises. It has been suggested that by providing information and raising awareness about PA, health care providers can augment the self-confidence of elderly individuals to begin exercise regimens [18].

\section{Environmental factors}

A lack of sports facilities was considered to be an especially important barrier. In this regard, construction of playgrounds, sidewalks, parks, or other fitness facilities could motivate individuals to participate in exercise, such as walking. Governments play an important role in providing subsidies and funding for health facilities, such as health centers and walking paths [2]. It was found that a lack of adequate facilities in organizational settings led to a decrease in enthusiasm for PA [52]. Likewise, in Iran, a study confirmed that the presence of exercise facilities, parks, and walking or cycling routes increased elderly individuals' motivation to engage in PA [16].

Some studies have shown that the availability of a resting place, such as benches along walking paths, may facilitate walking among the elderly. In this regard, for the elderly, it is very important to ensure easy access to safe, beautiful, and interesting places for walking. For these reasons, the elderly were found to prefer routes with places for them to rest [25].

The weather, season, and temperature were identified as potential barriers. Nadri et al. [16], in Iran, reported that participants considered an inappropriate environment to be a barrier. In addition, other studies have shown relationships between natural changes (season, weather, and temperature) and the intensity of PA [25]. In general, more intense PA was observed in the spring (40.1\%), in sunny weather (76.8\%), and at moderate temperatures (56.2\%). Elderly individuals were found to engage in more frequent walking in sunny weather than in rainy weather, and their walking rate was higher at temperatures below $60^{\circ} \mathrm{F}$ than at high temperatures $\left(81^{\circ} \mathrm{F}\right)$. Schmidt et al. [53] reported that "unpleasant weather" such as cold, snow, and extreme heat was a barrier. In addition, a study confirmed that the weather was a potential barrier for the oldest old people [4].

It is worth mentioning that we found some similar barriers and motivators. In some reviewed studies, a link was found between the benefits of prayer and PA. The energy cost of Muslim daily prayers was about 80 calories per day, implying that daily prayers could be considered a form of PA [12,54].

There are two important implications of these findings. First, the factors identified as important herein should be analyzed with regard to gender. Second, it is necessary to consider geographical areas and the accessibility of facilities. Additionally, the type of intervention program (community- or individual-based) is an especially important factor for encouraging the elderly to participate in exercise.

This systematic review has the following limitations. First, no information was extracted on differences between men and women. Therefore, further research is needed to identify any such potential differences. Second, it is possible that differences existed among participants and authors in the definition of exercise and PA. Third, most studies were conducted in developed countries, which may have yielded country-specific results and decreased the generalizability of the findings. As a final limitation, due to inconsistencies and heterogeneity in the data gathering and analysis methods used in the quantitative articles, it was not feasible to conduct a meta-analysis.

\section{CONCLUSION}

This study presents a comprehensive literature review and analysis on the barriers and motivators to PA in the elderly. Most barriers involved the intrapersonal and interpersonal domains. According to the population composition of the countries that were analyzed-especially Iran-interventions to address this issue are essential. In addition, the elderly may have different perceptions of barriers and motivators that need to be considered.

\section{SUPPLEMENTARY MATERIALS}

Supplementary material is available at http://www.e-epih.org/.

\section{CONFLICT OF INTEREST}

The authors have no conflicts of interest to declare for this study.

\section{ACKNOWLEDGEMENTS}

This study is related to project No. 1396/56458 from the Student Research Committee, Shahid Beheshti University of Medical Sciences, Tehran, Iran. We would also like to express our appreciation of the Student Research Committee and Research and Technology Chancellor of Shahid Beheshti University of Medical Sciences for their financial support of this study.

\section{AUTHOR CONTRIBUTIONS}

Conceptualization: SY, AR. Data curation: SY, HMS. Formal analysis: SY, HMS, MG. Funding acquisition: SY, AR, HMS. Methodology: SY, AR, HMS, MG. Project administration: SY, AR. Visualization: SY. Writing - original draft: SY, HMS, MG, AR. Writing - review \& editing: SY, HMS. 


\section{ORCID}

Soudabeh Yarmohammadi: https://orcid.org/0000-0002-88624074; Hossein Mozafar Saadati: http://orcid.org/0000-0002-59923710; Mohtasham Ghaffari: http://orcid.org/0000-0003-1756-5297; Ali Ramezankhani: https://orcid.org/0000-0002-3109-1641

\section{REFERENCES}

1. Armstrong T, Bauman A, Davies J. Physical activity patterns of Australian adults: results of the 1999 National Physical Activity Survey; 2000 [cited 2019 Dec 9]. Available from: https://www. aihw.gov.au/getmedia/3efdc7d6-8ce8-4157-b7c9-b7eb72eee107/ papaa.pdf.aspx?inline $=$ true.

2. Justine M, Azizan A, Hassan V, Salleh Z, Manaf H. Barriers to participation in physical activity and exercise among middle-aged and elderly individuals. Singapore Med J 2013;54:581-586.

3. Allender S, Cowburn G, Foster C. Understanding participation in sport and physical activity among children and adults: a review of qualitative studies. Health Educ Res 2006;21:826-835.

4. Baert V, Gorus E, Mets T, Geerts C, Bautmans I. Motivators and barriers for physical activity in the oldest old: a systematic review. Ageing Res Rev 2011;10:464-474.

5. World Health Organization. Global action plan for the prevention and control of NCDs 2013-2020 [cited 2019 Dec 10]. Available from: https://www.who.int/nmh/events/ncd_action_plan/en/.

6. Golden SD, Earp JA. Social ecological approaches to individuals and their contexts: twenty years of health education \& behavior health promotion interventions. Health Educ Behav 2012;39:364372.

7. Sallis JF, Cervero RB, Ascher W, Henderson KA, Kraft MK, Kerr J. An ecological approach to creating active living communities. Annu Rev Public Health 2006;27:297-322.

8. McLeroy KR, Bibeau D, Steckler A, Glanz K. An ecological perspective on health promotion programs. Health Educ Q 1988; 15:351-377.

9. Zeng X, Zhang Y, Kwong JS, Zhang C, Li S, Sun F, et al. The methodological quality assessment tools for preclinical and clinical studies, systematic review and meta-analysis, and clinical practice guideline: a systematic review. J Evid Based Med 2015;8:2-10.

10. Wells GA, Shea B, O'Connell D, Peterson J, Welch V, Losos M, et al. The Newcastle-Ottawa Scale (NOS) for assessing the quality of nonrandomised studies in meta-analyses [cited 2019 Jun 1]. Available from: http://www.ohri.ca/programs/clinical_epidemiology/ oxford.asp.

11. Yoo S, Kim DH. Perceived urban neighborhood environment for physical activity of older adults in Seoul, Korea: a multimethod qualitative study. Prev Med 2017;103S:S90-S98.

12. Horne M, Skelton DA, Speed S, Todd C. Attitudes and beliefs to the uptake and maintenance of physical activity among community-dwelling South Asians aged 60-70 years: a qualitative study. Public Health 2012;126:417-423.

13. Welmer AK, Mörck A, Dahlin-Ivanoff S. Physical activity in peo- ple age 80 years and older as a means of counteracting disability, balanced in relation to frailty. J Aging Phys Act 2012;20:317-331.

14. Simmonds BA, Hannam KJ, Fox KR, Tobias JH. An exploration of barriers and facilitators to older adults' participation in higher impact physical activity and bone health: a qualitative study. Osteoporos Int 2016;27:979-987.

15. Bethancourt HJ, Rosenberg DE, Beatty T, Arterburn DE. Barriers to and facilitators of physical activity program use among older adults. Clin Med Res 2014;12:10-20.

16. Nadri A, Safania AM, Amritash AM. Determinant of the implementation of physical activities in elderly in Tehran. J Gerontol 2016;1:66-79 (Persian).

17. Costello E, Kafchinski M, Vrazel J, Sullivan P. Motivators, barriers, and beliefs regarding physical activity in an older adult population. J Geriatr Phys Ther 2011;34:138-147.

18. de Groot GC, Fagerström L. Older adults' motivating factors and barriers to exercise to prevent falls. Scand J Occup Ther 2011;18: 153-160.

19. Lees FD, Clarkr PG, Nigg CR, Newman P. Barriers to exercise behavior among older adults: a focus-group study. J Aging Phys Act 2005;13:23-33.

20. Grossman MD, Stewart AL. "You aren't going to get better by just sitting around": physical activity perceptions, motivations, and barriers in adults 75 years of age or older. Am J Geriatr Cardiol 2003;12:33-37.

21. Chastin SF, Fitzpatrick N, Andrews M, DiCroce N. Determinants of sedentary behavior, motivation, barriers and strategies to reduce sitting time in older women: a qualitative investigation. Int J Environ Res Public Health 2014;11:773-791.

22. Chen YJ, Matsuoka RH, Tsai KC. Spatial measurement of mobility barriers: improving the environment of community-dwelling older adults in Taiwan. J Aging Phys Act 2015;23:286-297.

23. Chippendale T, Boltz M. The neighborhood environment: perceived fall risk, resources, and strategies for fall prevention. Gerontologist 2015;55:575-583.

24. Miller W, Brown PR. Motivators, facilitators, and barriers to physical activity in older adults: a qualitative study. Holist Nurs Pract 2017;31:216-224.

25. Price AE, Reed JA, Long S, Maslow AL, Hooker SP. The association of natural elements with physical activity intensity during trail use by older adults. J Phys Act Health 2012;9:718-723.

26. Van Holle V, Van Cauwenberg J, Deforche B, Van de Weghe N, De Bourdeaudhuij I, Van Dyck D. Do psychosocial factors moderate the association between objective neighborhood walkability and older adults' physical activity? Health Place 2015;34:118-125.

27. Eronen J, von Bonsdorff MB, Törmäkangas T, Rantakokko M, Portegijs E, Viljanen A, et al. Barriers to outdoor physical activity and unmet physical activity need in older adults. Prev Med 2014; 67:106-111.

28. Patel A, Schofield GM, Kolt GS, Keogh JW. Perceived barriers, benefits, and motives for physical activity: two primary-care physical activity prescription programs. J Aging Phys Act 2013;21:8599. 
29. Cohen-Mansfield J, Marx MS, Biddison JR, Guralnik JM. Socioenvironmental exercise preferences among older adults. Prev Med 2004;38:804-811.

30. Yi X, Pope Z, Gao Z, Wang S, Pan F, Yan J, et al. Associations between individual and environmental factors and habitual physical activity among older Chinese adults: a social-ecological perspective. J Sport Health Sci 2016;5:315-321.

31. Rantakokko M, Iwarsson S, Hirvensalo M, Leinonen R, Heikkinen E, Rantanen T. Unmet physical activity need in old age. J Am Geriatr Soc 2010;58:707-712.

32. Rowiński R, Morgulec-Adamowicz N, Ogonowska-Slodownik A, Dąbrowski A, Geigle PR. Participation in leisure activities and tourism among older people with and without disabilities in Poland. Arch Gerontol Geriatr 2017;73:82-88.

33. Bird S, Radermacher H, Feldman S, Sims J, Kurowski W, Browning $\mathrm{C}$, et al. Factors influencing the physical activity levels of older people from culturally-diverse communities: an Australian experience. Ageing Soc 2009;29:1275-1294.

34. Macniven R, Pye V, Merom D, Milat A, Monger C, Bauman A, et al. Barriers and enablers to physical activity among older Australians who want to increase their physical activity levels. J Phys Act Health 2014;11:1420-1429.

35. Bird S, Kurowski W, Feldman S, Browning C, Lau R, Radermacher $\mathrm{H}$, et al. The influence of the built environment and other factors on the physical activity of older women from different ethnic communities. J Women Aging 2009;21:33-47.

36. Kowal J, Fortier MS. Physical activity behavior change in middleaged and older women: the role of barriers and of environmental characteristics. J Behav Med 2007;30:233-242.

37. Newson RS, Kemps EB. Factors that promote and prevent exercise engagement in older adults. J Aging Health 2007;19:470-481.

38. Gillette DB, Petrescu-Prahova M, Herting JR, Belza B. A pilot study of determinants of ongoing participation in EnhanceFitness, a community-based group exercise program for older adults. J Geriatr Phys Ther 2015;38:194-201.

39. Thornton CM, Kerr J, Conway TL, Saelens BE, Sallis JF, Ahn DK, et al. Physical activity in older adults: an ecological approach. Ann Behav Med 2017;51:159-169.

40. Salehi L, Taghdisi MH, Ghasemi H, Shokervash B. To identify the facilitator and barrier factors of physical activity among elderly people in Tehran. Iran J Epidemiol 2010;6:7-15 (Persian).

41. Nejati V, Kordi R, Shoaee F. Evaluation of effective motivators and barriers of physical activity in the elderly. Iran J Ageing 2010; 4:52-58 (Persian).

42. Khalili Z, Sadrollahi A, Khatir Ahmadi M, Mossadegh N, Hosseinian M, Masoudi Alavi N. Relationship of physical activity facilitators and body mass index in Kashan elderly. Elder Health J 2015;1:84-90.

43. Shiraly R, Shayan Z, Keshtkar V, Hamed M. Self-reported factors associated with engagement in moderate to vigorous physical activity among elderly people: a population-based study. Int J Prev Med 2017;8:26.

44. Sharifian AS. Evaluation of the participation and inhibitors factors of sports activities in elderly. Strateg Stud Youth Sports 2014;12: 177-189 (Persian).

45. Resnick B, Vogel A, Luisi D. Motivating minority older adults to exercise. Cultur Divers Ethnic Minor Psychol 2006;12:17-29.

46. Dye CJ, Wilcox S. Beliefs of low-income and rural older women regarding physical activity: you have to want to make your life better. Women Health 2006;43:115-134.

47. Bauman AE, Reis RS, Sallis JF, Wells JC, Loos RJ, Martin BW, et al. Correlates of physical activity: why are some people physically active and others not? Lancet 2012;380:258-271.

48. Afshar PF, Asgari P, Shiri M, Bahramnezhad F. A review of the Iran's elderly status according to the census records. Galen Med J 2016;5:1-6.

49. Lim K, Taylor L. Factors associated with physical activity among older people--a population-based study. Prev Med 2005;40:33-40.

50. Mathews AE, Laditka SB, Laditka JN, Wilcox S, Corwin SJ, Liu R, et al. Older adults' perceived physical activity enablers and barriers: a multicultural perspective. J Aging Phys Act 2010;18:119140.

51. Hughes ME, Waite LJ, LaPierre TA, Luo Y. All in the family: the impact of caring for grandchildren on grandparents' health. J Gerontol B Psychol Sci Soc Sci 2007;62:S108-S119.

52. Chen YM. Perceived barriers to physical activity among older adults residing in long-term care institutions. J Clin Nurs 2010; 19:432-439.

53. Schmidt L, Rempel G, Murray TC, McHugh TL, Vallance JK. Exploring beliefs around physical activity among older adults in rural Canada. Int J Qual Stud Health Well-being 2016;11:32914.

54. Kamran G. Physical benefits of (Salah) prayer-strengthen the faith and fitness. J Nov Physiother Rehabil 2018;2:43-53. 